\title{
UNA TESIS SOBRE LA NATURALEZA Y LAS CARACTERÍSTICAS DE LA OBLIGACIÓN TRIBUTARIA*
}

\author{
A Thesis on the Nature and \\ Characteristics of the Tax \\ Obligation
}

\author{
UMA TESE SOBRE A NATUREZA \\ E AS CARACTERÍSTICAS DA \\ OBRIGAÇÃO TRIBUTÁRIA
}

\begin{abstract}
PATRICIO MASBERNAT***
* $\quad$ Este artículo forma parte del proyecto FONDECyT Regular 1140290 (“Evaluación crítica y reconstrucción dogmática del concepto y los perfiles del tributo en el sistema jurídico chileno, y sus parámetros justificativos, particularmente fines extrafiscales"); y del proyecto de investigación DIUA109-2017 titulado "Sistematización y evaluación de las teorías de la relación jurídica tributaria en Chile, desde la perspectiva del desarrollo científico actual del Derecho Comparado", financiado por la Vicerrectoria de Investigación y Postgrado de la Universidad Autónoma de Chile. El autor es Investigador Responsable. El autor agradece las interesantes observaciones y los comentarios efectuados por los pares evaluadores de la revista Dikaion, que han contribuido inestimablemente a enriquecer el artículo y otorgarle un mayor enfoque dialéctico.

** orcid.org/0000-0001-7137-9474. Universidad Autónoma de Chile, Chile. patricio.masbernat@uautonoma.cl.
\end{abstract}

RECIBIDO: 26 DE JUNIO DE 2016. ENVÍO A PARES: 23 DE ABRIL DE 2017 APROBADO POR PARES: 19 DE MAYO DE 2017. ACEPTADO: O7 DE JUNIO DE 2017 


\section{RESUMEN}

El presente artículo tiene por objeto presentar una evaluación de la concepción estándar de la obligación tributaria, y exponerla como una obligación casuística derivada de la relación jurídica tributaria, que sería más compatible con la idea de ciudadanía y Estado constitucional y democrático de derecho. A juicio del autor, la relación jurídica tributaria estaría mejor representada como perteneciente a un estatuto que vincula al Estado con el ciudadano en cuanto obligado tributario en general, y contribuyente en particular, y que es el producto principal de la potestad tributaria; de dicho estatuto nacerian obligaciones tributarias de diversa naturaleza. Que la obligación tributaria sea casuística implica que su contenido es específico y deriva de determinadas operaciones de distinta naturaleza y de decisiones institucionales. El fundamento de la obligación se encontraria, a juicio del autor, en todas las normas del sistema aplicables al caso. Por tanto, la obligación tributaria sería compleja, sistémica y dinámica. La obligación tributaria se debe distinguir enteramente del tributo, el cual solo presenta un contenido abstracto útil para especificar el contenido del derecho tributario, y, por tanto, de la construcción general que sustenta dogmáticamente el sistema tributario.

\section{PALABRAS CLAVE}

Tributo; obligación; potestad; tributación; legalidad. 


\section{ABSTRACT}

The purpose of this article is to offer an assessment of the standard notion of the tax obligation and to present it as a casuistic obligation derived from the tax legal relationship, which would be more compatible with the idea of citizenship and constitutional and democratic rule of law. The author believes the tax legal relationship would be better represented as pertaining to a statute that links the State with the citizen in terms of being liable for taxes, in general, and a taxpayer in particular, and is the main product of tax authority. The statute would give rise to various sorts of tax obligations. That the tax obligation is casuistic implies its content is specific and derives from certain operations of distinct nature and from institutional decisions. In the opinion of the author, the basis of the obligation would be found in all the rules of the system that are applicable to the case. Therefore, the tax obligation would be complex, systemic and dynamic. It must be distinguished entirely from the tax itself, which only affords an abstract content that is useful to specify the content of tax law and, therefore, the general construction that dogmatically supports the tax system.

\section{KEYWORDS}

Tax; obligation; authority; taxation; legality. 


\section{RESUMO}

Este artigo tem como objetivo apresentar uma avaliação do conceito-padrão de obrigação tributária e expô-la como uma obrigação casuística derivada da relação jurídica tributária, que seria mais compativel com a ideia de cidadania e Estado constitucional e democrático de direito. Segundo o julgamento do autor, a relação jurídica tributária estaria mais bem representada como pertencente a um estatuto que vincula o Estado com o cidadão enquanto obrigado tributário, em geral, e contribuinte, em particular, e que é o produto principal do poder tributário; desse estatuto nasceriam obrigações tributárias de diversa natureza. $\mathrm{O}$ fato de a obrigação tributária ser casuística implica que seu conteúdo seja especifico e que derive de determinadas operações de diferente natureza e de decisões institucionais. O fundamento da obrigação se encontraria, segundo o autor, em todas as normas do sistema aplicáveis ao caso. Portanto, a obrigação tributária seria complexa, sistêmica e dinâmica. Além disso, ela deve se diferenciar completamente do tributo, o qual só apresenta conteúdo abstrato útil para especificar o conteúdo do direito tributário, e, portanto, da construção geral que sustenta dogmaticamente o sistema tributário.

\section{PALAVRAS-CHAVE}

Legalidade; obrigação; potestade; tributo; tributação. 
SUMARIO: INTRODUCCIÓN; 1. EL TRIBUTO COMO INSTITUTO DISTINTO DE LA OBLIGACIÓN TRIBUTARIA Y DE LA RELACIÓN JURÍDICO TRIBUTARIA; 2. POTESTAD TRIBUTARIA COMO FUNDAMENTO TEÓRICO DE LA RELACIÓN JURÍDICA TRIBUTARIA; 3. LA RELACIÓN JURÍDICA TRIBUTARIA Y LA OBLIGACIÓN TRIBUTARIA; 4. NUESTRA PERSPECTIVA DE LA RELACIÓN JURÍDICA TRIBUTARIA Y LA OBLIGACIÓN TRIBUTARIA; BIBLIOGRAFÍA.

\section{INTRODUCCIÓN}

El objetivo del presente trabajo es exponer una perspectiva o explicación (no una teoría completa) de las instituciones de derecho tributario que se abordan. En un espacio tan breve no es posible (ni es el objetivo) revisar las teorías de la relación jurídica tributaria (RJT) y de la obligación tributaria (OT), sino dialogar con las tesis y las categorías comúnmente usadas, desde un prisma crítico, que permita exponer al menos dos ideas básicas: una comprensión sistémica de la RJT y de la OT mediada por el contenido del ordenamiento jurídico que fuere pertinente: su comprensión desde una perspectiva de razonamiento práctico y no solo desde el razonamiento teórico, en que la interpretación y aplicación frente al caso resultan cruciales para entender las categorías jurídico-tributarias indicadas.

Para esto, se comenzará por distinguir el concepto de tributo del contenido de la OT y la RJT, que han sido por muchos identificadas mutuamente, y estas a su vez, con la categoria de tributo. De esta confusión conceptual nacen algunos planteamientos que detallaremos y no compartimos.

Asimismo, es necesario referirse a la idea de potestad tributaria, dado que de esta surge un producto (la ley tributaria formulada de un modo determinado) que se encuentra legitimado por la concepción de la función que a dicha potestad se atribuya. Asimismo, dicha ley establecerá el contenido de la RJT y su forma de aplicarla), es decir, el vínculo entre el Estado y el contribuyente.

Desde el enfoque expuesto en este artículo, resulta posible observar a un contribuyente vinculado a un estatuto de derecho público (como no podría ser de otra manera), de carácter propiamente tributario, que lo lleva a ocupar una determinada posición jurídica dentro del ordenamiento, por lo que resulta entonces vinculado de modo global a este por su carácter de habitante de un Estado, ciudadano y contribuyente, y no solo por realizar un hecho gravado específico. A su vez, la forma de entender al obligado tributario es como ciudadano, y al Estado solo como un sujeto de la RJT, y que ejerce sus potestades y se encuentra obligado (condicionado y sujeto a derecho) en el marco de un Estado constitucional de derecho. Es decir, de algún modo, el prisma crítico planteado propone una determinada mirada global sobre las piezas ya existentes del sistema jurídico (e incluso de las teorías vigentes), sin ser necesario reinterpretarlas o mutarlas en su contenido, sino solo comprender la posición del contribuyente como un ciudadano vincula- 
do de modo permanente al sistema jurídico tributario y no solo cuando realiza el hecho imponible.

A partir de ese punto, se abre el análisis acerca de las consecuencias del planteamiento efectuado. Desde nuestra perspectiva es posible defender que las consecuencias deben ser en gran medida determinadas en el juego dialéctico de aplicación institucional de las normas tributarias, es decir, en sede legislativa, administrativa, judicial, de justicia constitucional, etc., en el contexto de un orden institucional de democracia constitucional.

Para exponer estas ideas, en primer término se abordará el concepto de tributo, OT y RJT; la dinámica de la teoría de la potestad tributaria y la RJT; para finalmente plantear el prisma central defendido por el autor en este artículo, cual es la comprensión del sistema jurídico tributario como un estatuto jurídico y la categoría de relación jurídica tributaria de carácter estatutario. Dados los límites de espacio permitido para este artículo, no resulta posible profundizar demasiado en cada uno de los asuntos indicados, por lo que deberemos mencionar publicaciones efectuadas en otras revistas donde se profundizan algunos aspectos de dichos temas.

\section{EL TRIBUTO COMO INSTITUTO DISTINTO DE LA OBLIGACIÓN TRIBUTARIA Y DE LA RELACIÓN JURÍDICO-TRIBUTARIA ${ }^{1}$}

En este apartado se pretende mostrar que el tributo constituye un instituto enteramente distinguible de la OT y de la RJT. La distinción mencionada no es un asunto obvio como se pudiera pensar, dado que hoy persiste un fuerte vínculo teórico entre dichas instituciones que ha conducido a una cierta confusión conceptual, la cual incide en un cierto enfoque de la RJT alejado de la perspectiva que se defiende en este artículo. ${ }^{2}$

1 Para ampliar información respecto de los asuntos referidos en este acápite, y las opiniones del autor, ver: Patricio Masbernat, "El concepto de tributo y sus finalidades u objetivos", Revista Tributária e de Finanças Públicas: RTrib 24 (129) (2016), pp. 155-192.

2 La vinculación entre tributo, hecho imponible, OT, RJT es tan fuerte, que conduce a explicaciones como la de Miguel Ángel Martínez LaGo (El tributo: concepto y clases, en Base de datos Iustel, RI §91173, fecha de consulta: 10 de abril de 2017): "Estructuralmente el tributo consiste en (o está instrumentado como) un vínculo jurídico obligacional, que en su naturaleza o 'esencia' es conceptualmente idéntico al de cualquier otra obligación, encontrando su disciplina común, en lo que no se oponga a la muy diversa función a cumplir en este campo, en el derecho general de obligaciones. Ahora bien, ello no quiere decir que ambos tipos de obligaciones, la privada y la tributaria, sean idénticas en todas sus características ni, mucho menos, que ambas partes de la relación - acreedor y deudor- se sitúen en el mismo nivel. Es cierto que la Administración está sujeta totalmente a la ley del mismo modo que el particular, pero sin embargo la función pública atribuida a la Administración explica su posición de imperium, exorbitante de la de un acreedor privado". 
Buscamos mostrar que el problema del tributo, el debate acerca de su naturaleza y contenido, es uno muy diferente al debate acerca de la $\mathrm{RJT}^{3}$ o de la OT. ${ }^{4}$ Resulta necesario enfatizar esta distancia para mostrar la posición jurídica del obligado tributario, es decir, la cuestión de cómo este se encuentra vinculado al sistema tributario (es decir, cómo opera en relación con él la LRJ).

El tributo constituye una institución, ${ }^{5}$ pues se trata de una categoría compleja y nuclear para determinada clase o tipo de relaciones jurídicas y, asimismo, se comprende a través de una serie de reglas, principios y objetivos. Como institución, el tributo se compone de conceptos, principios y estructuras más o menos universales que trascienden las regulaciones locales (características de las relaciones jurídicas de que da cuenta), y a partir de él se desarrolla una rama del ordenamiento jurídico, y permite dialogar con otros ordenamientos jurídicos mediante mecanismos de derecho privado, derecho público, derecho internacional, etc. Mediante esa institución (el tributo) se logra identificar un conjunto de normas y tipos de casos como propias de una rama del derecho o pertenecientes o regladoras de la RJT. ${ }^{6}$ El concepto en análisis se ubica en la teoría general del tributo. Esta última contiene elementos tales como: potestad tributaria; fines del tributo (fiscales y extrafiscales); características, elementos y clases de tributos; principios materiales (de justicia) y formales del tributo; RJT y OT, etc. El concepto clásico de tributo y

3 De modo muy general, desde el derecho positivo es posible indagar ejemplos de leyes que abordan estos temas. La Ley General Tributaria de España, en su art. 17 define la RJT como "el conjunto de obligaciones y deberes, derechos y potestades originados por la aplicación de los tributos”, de la que derivan obligaciones tributarias que pueden tener un carácter formal o un carácter material, y las accesorias. Las obligaciones materiales son las de pago de la cuota tributaria (pago del tributo), de realizar pagos a cuenta (LGT art. 23). Los elementos de la OT: hecho imponible (art. 20 LGT); el devengo (art. 21 LGT); las exenciones. El art. 24 LGT menciona las obligaciones entre particulares; obligaciones tributarias accesorias en el art. 25 LGT; obligaciones tributarias formales en el art. 29 LGT. Por otro lado, el Código Tributario Modelo CIAT de 2015, el cual define en el art. 19 la RJT (como relación de derecho) y en art. 20 las obligaciones tributarias, materiales y formales, para sujeto activo y pasivo. Es interesante porque incluye comentarios.

4 BATISToni sostiene que "L'obbligazione è generalmente considerata, dalla dottrina prevalente e dalla giurisprudenza, come il momento centrale della relazione istituita tra ente impositore e contribuente: la situazione nella quale si esprime e manifesta, in concreto, la potestà d'imposizione rispetto al singolo soggetto. La dottrina è però divisa in ordine ad una pluralità di aspetti. Opinioni diverse, infatti, si manifestano rispetto alla indefettibilità dell'obbligazione come strumento per l'acquisizione di somme a titolo di tributo, sul rapporto tra obbligazione tributaria ed obbligazioni di diritto civile, sul momento genetico dell'obbligazione e sulle caratteristiche che distinguerebbero particolari situazioni proprie del diritto tributario impedendone l'assimilazione agli istituti di carattere civile”. Franco Batistoni, Obbligazioni nel diritto tributario, Torino, Digesto, Leggi di Italia, 1994.

5 Pérez de Ayala lo explica de este modo: "Es una institución jurídica. El vocablo institución ha sido objeto de muchos usos diversos por parte de los juristas, hasta el punto de que algún jurista ilustre prefiere, por ello, no usarlo. Sin embargo, resulta útil didácticamente comenzar advirtiendo que el tributo es una Institución jurídica, si se admite un concepto dado de institución, compartido, por otra parte, por un amplio y autorizado sector doctrinal. En efecto, si nosotros admitimos que existe una institución jurídica siempre que existe una serie orgánica de normas que regulan relaciones jurídicas, un conjunto de disposiciones de derecho relativas a relaciones jurídicas de una clase determinada (enneccerus), hemos de admitir también que el tributo es una Institución jurídica". José Luis Pérez De Ayala et al., Fundamentos de derecho tributario, Madrid, Dykinson, 2013, p. 53.

6 La institución jurídica está ligada a los conceptos de norma y relación jurídica, al concepto de ordenamiento jurídico, y reúne relaciones jurídicas con caracteres comunes. Phillipe JESTAZ, El derecho, Santiago de Chile, Editorial Jurídica de Chile (traducción de la $2^{\text {a }}$ edición original, Le Droit, Paris, Editions Dalloz, 1992, p. 32). 
sus subcategorias, tales como la parafiscalidad, está comprendido dentro del fenómeno de la fiscalidad. Si bien existe un cierto acuerdo de la doctrina respecto del concepto de tributo, ${ }^{7}$ este se encuentra en continua revisión. ${ }^{8}$

Detrás del concepto de tributo existe una racionalidad en su construcción científica, ${ }^{9}$ en términos de coherencia con el ordenamiento jurídico y sus elementos, entre ellos, el principio de Estado de derecho, los derechos humanos, etc.

El tributo responde a ciertas condiciones básicas: es exigible para que el Estado financie un determinado tipo de bienes (servicios públicos en general, a través de órganos públicos) respecto de los cuales debe ocuparse porque el mercado no quiere o no puede (limites económicos), o no debe hacerlo (limites morales y políticos); esas funciones son básicas o especiales, propias de la razón de ser del Estado, y de su organización política.

Los tributos constituyen una detracción coactiva de riqueza privada mediante normas de derecho público. Implican una transferencia de riqueza o propiedad desde un patrimonio hacia otro patrimonio (a nuestro juicio, no se limita a un órgano público y a un presupuesto público); son coactivos y obligatorios (a nuestro juicio, en un sentido muy amplio); exigidos por una decisión de carácter público (normas de derecho público); en razón de fines declarados como públicos. Por ello, hemos sostenido que toda regulación que implique cobro a usuarios sobre bienes públicos o colectivos es tributo, tipicamente las concesiones; toda exacción referida a bienes o servicios que tienen relación con bienes que deben ser provistos por el Estado por razones económicas, políticas o éticas, típicamente bienes públicos (v. g., cobertura de derechos económicos y sociales; de derechos fundamentales). ${ }^{10}$

7 César García NovoA, El concepto de tributo, Buenos Aires, Marcial Pons, 2012.

8 Patricio MAsBernat, "Retorno al debate conceptual de tasa y tarifa como un parámetro de los límites del concepto de tributo. Comentario a la sentencia del Tribunal Supremo de España 5037/2015, de 23 de noviembre de 2015, recaído en recurso de casación 4091/2013", en Revista chilena de derecho, 2017.

9 Una perspectiva racional implica un método crítico (derivado de la ciencia jurídica racionalista y de la ciencia jurídica contemporánea) (Manuel Calvo García, Teoría del derecho, 2 ed., Madrid, Tecnos, 2000, pp. 18-22), y se opone a la racionalización y el idealismo, que consiste en explicar el mundo por las ideas y tomar estas como la expresión de la realidad, en tomar la realidad del derecho por la realidad concreta. Aplicado a nuestro objeto de estudio, no cabe considerar que el tributo es aquello descrito como tal por el legislador, el único método posible sería la exegesis y se vedaría la construcción científica de las instituciones. Phillipe Jestaz, El derecho, op. cit., p. 103.

10 Esto lo expresa bien Kelman, quien sostiene que "la regulación y la tributación son sustitutos uno para el otro" ("regulation and taxation are substitutes one for the other") y permiten al Estado lograr sus objetivos políticos, a través de programas de gasto público ("public spending programs") financiados por tributos (taxes) o mediante mandatos regulatorios que incidan en conductas de los particulares; y al contrario, limitan a los ciudadanos el disfrute pleno y libre de los frutos de su empresa. El asunto constitucionalmente crítico no está compuesto por los objetivos de la legislación social, sino por quienes pagan el logro de estos. KELMAn aborda esto desde la perspectiva del Derecho Constitucional y de la Política Regulatoria (regulatory policy), y se pregunta acerca de ¿cuándo es permisible regular en lugar de utilizar los programas de impuestos y transferencias (tax-and-transfer programs)? Mark Kelman, Streategy or Principle? The Choice Between Regulation and Taxation, 4 edition, Michigan, The University of Michigan Press, 1999, p. 44. 
Por ello, la noción más amplia y para nosotros más precisa, sería la de exacciones obligatorias. ${ }^{11}$ A partir de ello pueden incorporarse otras características y requisitos. ${ }^{12}$ Con todo, las clases de tributos no solo deben considerarse vinculadas a impuestos, tasas ${ }^{13}$ y contribuciones, sino también, como se quiera denominar, a otra clase de tributos o impuestos de toda naturaleza, ${ }^{14}$ e incluso en ciertos casos los monopolios. ${ }^{15}$ Asimismo, debe considerarse la idea de parafiscalidad. ${ }^{16}$ Esta última categoria, muy difundida en países que externalizan la actividad del Estado (como Chile), y que utilizan como herramienta de politica pública destinada a conseguir más recaudación (indirecta) sin verse limitada por las exigencias a que es sometido todo tributo (incluidos los derechos fundamentales del modo incorporado en el estatuto del tributo) debiera ser limitada o regulada por constituir una situación anómala en relación con la racionalidad y coherencia del sistema jurídico en general, y del sistema tributario en particular. ${ }^{17}$ La parafiscalidad (y cualquier exacción de efecto equivalente, como las prestaciones patrimoniales públicas en sentido estricto), parafraseando a Varona, constituyen patologias que deben ser corregidas "ya que generan una incontrolada y perturbadora presión fiscal paralela", y agrega dicho autor, que

... este fenómeno presenta una gradación, en función al mayor o menor respeto que se conceda a aquellos cauces y según la magnitud de aquellas anomalías, debiendo destacarse que las más perniciosas y que mayor grado de parafiscalidad confieren son la deslegalización y la exclusión de los presupuestos públicos, irregularidades que hoy deben reputarse inconstitucionales. ${ }^{18}$

En definitiva, una concepción material y amplia resulta necesaria para tutelar los derechos de las personas frente al Estado en el contexto de un Estado constitucional de derecho que construya la RJT sobre la base de un vínculo de ciudadanía.

11 Pierre Beltrame, Introducción a la fiscalidad en Francia, Barcelona, Atelier, 2004, p. 22.

12 Estela Rivas, Los tributos atípicos, Madrid, Marcial Pons, 2006; César García Novoa, El concepto de tributo, op. cit.

13 Las tasas se distinguen de precios públicos, tarifas, cánones (Enrico De Mrta, Principi di Diritto Tributario, Giuffre Editore, 2011, p. 5). Las categorias específicas son discutibles en su clasificación, ya que usualmente caen en la parafiscalidad como explica Rivas, Los tributos atípicos, op. cit. Sin embargo, estas categorías son defendidas como prestaciones patrimoniales públicas de carácter no tributario, muy usualmente (Francisco José VILLAR RoJAs, Tarifas, tasa, peajes y precios administrativos, Granada, Comares, 2000).

14 Pierre Beltrame, Introducción a la fiscalidad en Francia, op. cit., p. 29.

15 José Juan Ferreiro Lapatza, Instituciones de derecho tributario, Madrid, Marcial Pons, 2010, p. 91.

16 Estela Rivas, Los tributos atípicos, op. cit. El tributo se diferencia de otras detracciones de riqueza coactiva tales como la expropiación, imposiciones de límites, sanciones, etc., porque tiene por fin satisfacer necesidades públicas. Con todo, puede perseguir fines fiscales o extrafiscales (F. TESAURo, Compendio di Diritto Tributario, 4 ed., Italia, UTET, 2012, p. 3).

17 Estela Rivas, Los tributos atípicos, op. cit., p. 17. José Maria, Moreno SeiJAs, "La tasa y el precio público como instrumentos de financiación”, IEF, Madrid, P.T. 7/98, p. 10.

18 Juan Enrique Varona, Los tributos extrafiscales. Extrafiscalidad regular e irregular. Tratado sobre la Ley General Tributaria: homenaje a A. Rodríguez Bereijo, A. BAEz y D. JimÉnEz (coords.), Dialnet, 2010, p. 41. 


\section{POTESTAD TRIBUTARIA COMO FUNDAMENTO TEÓRICO DE LA RELACIÓN JURÍDICA TRIBUTARIA}

La potestad tributaria o poder tributario ha sido definida como la "potestad de crear y establecer los tributos por norma de rango de ley", ${ }^{19}$ y de acuerdo con las tesis mayoritarias es expresión nuclear de soberanía ${ }^{20}$ y poder ${ }^{21}$ (lo que lleva a reflexionar acerca de que no siempre se alcanzan a comprender las implicancias del constitucionalismo democrático en relación con la concepción teórica de dicha la potestad), y este poder de sujeción e imperio tiene por objeto la imposición de tributos como obligaciones de pago y la creación de medios de aseguramiento de dicha finalidad. ${ }^{22}$ En este contexto, se menciona de un modo no siempre distinguible al Estado legislador (creador del sistema de exacciones patrimoniales obligatorias) y al Estado ejecutor de las exigencias nacidas de las leyes (administración tributaria), ${ }^{23}$ aludiendo a un conjunto de potestades, derechos y prerrogativas del sujeto activo, con múltiples expresiones. ${ }^{24}$ La potestad tributaria (poder político) se puede distinguir de la potestad de imposición (potestad administrativa). ${ }^{25}$ No obstante, no es posible escindir la potestad tributaria de otras situaciones en que se encuentra la administración (tales como el derecho de crédito, a la percepción de los tributos). ${ }^{26}$

La potestad tributaria se ejerce mediante la ley, la que crea el tributo, el que se configura como un vínculo jurídico, esto es, como un deber de pagar. Dicha

19 José luis Pérez De Ayala et al., Fundamentos de derecho tributario, op. cit. La construcción en Estados Unidos es diferente, como se observa en EDREY (Constitutional Review and Tax Law: an Analytical Framework, American University Law Review 56 (5) (2007), pp. 1187-1228), la que a su vez se desarrolló sobre algunas bases distintas que en Inglaterra (John Tiley y Gleen LouTZENHISER, Revenue Law, Oxford, Hart Publishing, 2012, p. 30), no obstante que hoy todos los sistemas juridicos tributarios parecen converger por influencia de principios constitucionales comunes.

20 Juan Martín y Carmelo Lozano, Curso de derecho financiero y tributario, Madrid, Tecnos, 2013, p. 143.

21 Al respecto, es ilustrativo el concepto clásico de soberanía que sostienen Aylwin y AzocAR, para quienes la "soberanía es la cualidad que tiene el Estado de no hallarse obligado sino por su propia voluntad y de imponer esa voluntad sobre todos los individuos o grupos que son miembros suyos o que se hallan dentro de su territorio". Patricio Aylwin y Eduardo Azocar, op. cit., p. 22.

22 José Luis Pérez De Ayala et al., Fundamentos de derecho tributario, op. cit., p. 3.

23 Como pone de relieve Queralt, "la relativa imprecisión de que está dotada la Administración en el ámbito tributario, ha venido propiciada por varios factores: [...] la no diferenciación entre Estado legislador o fuente del derecho, la Administración titular de potestades normativas y situaciones jurídicas ante el administrado, contribuyente o no". (Juan Martín Queralt, "La potestad tributaria”, en Tratado de derecho tributario, tomo I, Andrea Amatucci (director), Bogotá, Temis, 2001, p. 141).

24 Ibid., p. 142.

25 Por otro lado, la potestad de imposición "designa al conjunto de potestades administrativas establecidas para la aplicación jurídicamente correcta de los tributos, una vez creados, y puede simplificarse en tres fases o etapas: (a) La de definición y cuantificación de la obligación tributaria concreta de cada contribuyente, de acuerdo con la Ley creadora del impuesto: fase de investigación, comprobación y liquidación de la exacción. A menudo, la ley obliga al contribuyente a definir y cuantificar su obligación bajo el control ulterior de la Administración. (b) Fase en la que se hace efectiva la obligación tributaria ya definida y cuantificada: fase de recaudación. (En los casos en que la ley obliga al contribuyente a definir y cuantificar su deuda y declararla, también le obliga a ingresarla en el momento.) (c) Fase que, aun si puede superponerse a las anteriores en el tiempo, tiene por finalidad garantizar que las dos citadas anteriormente se desarrollan de acuerdo con lo establecido en la normativa reguladora de las correspondientes figuras fiscales" (José Luis Pérez De Ayala et al., Fundamentos de derecho tributario, op. cit., p. 42).

26 Juan Martín Martin Queralt, "La potestad tributaria”, op. cit., p. 143. 
potestad es manifestación del poder político, y produce distintas clases de normas tributarias. ${ }^{27}$

En definitiva, en el contexto de una concepción teñida de aspectos autoritarios ${ }^{28}$ y preconstitucionales, ${ }^{29}$ en el ejercicio de la potestad tributaria el Estado hace nacer, mediante la ley, la obligación tributaria y sus condiciones, el tributo que deberá pagar el obligado (contribuyente), y ejecuta dicha norma sujeta a sus propias perspectivas interpretativas, bajo la general impresión de que solo hace actuar a la ley. La potestad tributaria (potestad de legislar y de reglamentar) parece identificarse con la titularidad del crédito tributario (del tributo, en lenguaje usual de la doctrina) determinado en cada caso por un órgano estatal (Administración Tributaria, principalmente), por lo que parece consistente que se dote al acreedor (Estado) de potestades de ejecución en razón de la legitimidad del establecimiento de tributos (v. g., principio de solidaridad, gastos públicos, bien común, etc.), lo que a su vez tiene la virtualidad de legitimar la limitación de derechos fundamentales. Si se identifica la potestad tributaria con todos los pasos que conducen a la recolección de recursos financieros, ${ }^{30}$ es coherente unir en una sola mano el poder de legislar (establecer el tributo), el poder de determinar la OT (“aplicar” la ley), el poder de exigirla (ejecutar el crédito), y luego el poder de destinar dichos fondos a ciertos fines. Es coherente, pero estimamos que puede ser evaluado o modulado en el contexto actual de Estado constitucional y democrático de derecho.

Por otro lado, se sostiene que la potestad tributaria, en su ejercicio, debe sujetarse a una restricción básica, cual es, que el tributo o la OT debe imponerse por ley (a veces se usan los términos de modo intercambiable, también con los de cuota tributaria o deuda tributaria), ${ }^{31}$ suponiendo en tales términos la equivalencia con el principio de autoimposición, dado que ambos son diferentes y pertenecen a distintos ámbitos. ${ }^{32}$ Esta restricción es denominada principio de reserva de ley (aunque en Chile y Argentina suele denominársele principio de legalidad), ${ }^{33}$ que es uno de los principios formales de la tributación. ${ }^{34}$ Dado lo anterior, se afirma que la OT constituye una obligación ex lege, configurada dentro de la estructura de la relación jurídica tributaria ${ }^{35}$ (aunque en ocasiones se usa esta última categoría de modo intercambiable con la de $\mathrm{OT}^{36}$ o tributo). Desde una perspectiva completa, la

27 José Luis Pérez De Ayala et al., Fundamentos de derecho tributario, op. cit., p. 41.

28 Juan Martín Queralt, "La potestad tributaria”, op. cit., p. 145.

29 Las potestades nucleares de la soberanía son las de acuñar monedas, aplicar impuestos, declarar la guerra (Juan Martín Queralt, "La potestad tributaria”, op. cit., p. 143).

30 Carlos Giuliani Fonrouge, Derecho financiero 1 (10) (2011), Buenos Aires, La Ley, p. 314, "La expresión poder tributario significa la facultad o la posibilidad de exigir contribuciones con respecto a personas o bienes que se hallan en su jurisdicción”.

31 José Juan Ferreiro Lapatza, Instituciones de Derecho Tributario, op. cit., p. 219.

32 El principio de reserva de ley es normativo y formal, siendo suficiente que en un Estado una determinada norma jurídica se considere ley o asimilable a la ley. La autoimposición es un principio político de participación (democrática) en la generación de los tributos.

33 Osvaldo CASAS, Derechos y garantias constitucionales del contribuyente, Buenos Aires, Ad Hoc, 2002, p. 220.

34 Dicho principio implica tanto la participación (autoimposición) y expresión de derechos como la restricción o imposición de deberes.

35 Fernando Pérez Royo, Derecho financiero y tributario. Parte general, Pamplona, Thomson Reuter, 2011 , p. 134 .

36 José Juan Ferreiro Lapatza, Instituciones de derecho tributario, op. cit., p. 221. 
doctrina más avanzada comprende la relación jurídica tributaria a partir del deber constitucional de contribuir a los gastos públicos, ${ }^{37}$ configurando el concepto de tributo y de carga tributaria en general, ${ }^{38}$ y considerando los principios materiales sobre los cuales se debe construir el sistema tributario, ${ }^{39}$ y sus fines $\mathrm{u}$ objetivos fiscales y extrafiscales contenidos en la Constitución. ${ }^{40}$

\section{LA RELACIÓN JURÍDICA TRIBUTARIA Y LA OBLIGACIÓN TRIBUTARIA}

En derecho comparado, las teorias o concepciones de la RJT no han sido desarrolladas en iguales términos en todos los grupos de países, si bien las categorías jurídicas tributarias suelen ser las mismas, en el sentido de que se encuentran presentes en las regulaciones no obstante sus diferentes tratamientos normativos. ${ }^{41}$ Ha constituido un tema relevante en Italia, ${ }^{42}$ España $^{43}$ y Alemania, ${ }^{44}$ mien-

37 Francisco Escribano, La configuración jurídica del deber de contribuir, Perú, Edit. Jurídica Grijley, 2009; Cristina Pauner, El deber constitucional de contribuir al sostenimiento de los gastos públicos, Madrid, Centro de Estudios Políticos y Constitucionales, 2001.

38 César García Novoa, El concepto de tributo, op. cit.; José Juan Ferreiro Lapatza, Instituciones de derecho tributario, op. cit., pp. 219-268; Pierre Beltrame, Introducción a la fiscalidad en Francia, op. cit., pp. 21-33.

39 P. Masbernat, C. Billardi, J. A. Fernández y M. A. Sánchez, "Los principios materiales de la tributación en las constituciones de Argentina, España e Italia. Algunas luces para la construcción de una dogmática en Chile”, Revista de Derecho, Universidad Católica de Valparaíso, 2013; José Manuel Gallego, Los principios materiales de justicia tributaria, Granada, Comares, 2003; Felipe Romero, El valor sistema tributario, Cadiz, Universidad de Cádiz, 2005.

40 Juan Enrique VARona Alabern, "Extrafiscalidad irregular e imposición inmobiliaria”, Revista Quincena Fiscal 1 (2010), Pamplona, Estudio Editorial Aranzadi, 2010. BIB 2010 18; Eusebio GonZÁLEZ, "Los tributos extrafiscales en el derecho español", en Justicia y derecho tributario: libro homenaje al profesor Julio Banacloche Pérez, por C. Banacloche (coord.), 2008. Christian Aste es más sucinto, se refiere a los límites internos como limites de naturaleza constitucional. Esta es la posición general defendida en la doctrina chilena.

41 Cabe recordar lo que se planteó en un seminario internacional del año 2009 en la Universidad de Michigan: "According to Ault, understanding the solutions given by other countries to similar problems not only helps you to understand better the rules of your own country, but also helps you to find new and better solutions to similar problems in your own country (legal environment). As an example, all countries were looking for solutions from other legal systems before drafting e-commerce tax legislation. Arnold agreed with Ault, and he also believes that one should compare two or more tax legislations while drafting a tax rule, despite notable difficulties in conducting such a comparison in different jurisdictions, such as language differences. He provided as an example Australia's case of anti-avoidance legislation that distinguishes between 'misuse' and 'abuse', which has no parallel distinction in the French language, and as such is lost when applied in Guebec, Canada. Thuronyi added that much of his practice in drafting tax laws for developing countries was based on the study of comparative tax law. He also provided examples of where legal transplants had gone awry in this work, such as where a particular transplanted rule ended up playing a totally different and unintended role" (Reuven Avi-Yonaн et al., Comparative Tax Law: Theory and Practice, Bull. for Int'l Tax'n 64 (3) (2010), pp. 183-185).

42 Andrea Amatucci (coord.), Tratado de derecho tributario, Bogotá, Temis, 2001; Francesco Tesauro, Compendio di Diritto Tributario, 4 ed., Italia, Uteт, 2012, p. 44 y ss.; Giuseppe Tinelli, Istituzioni di Diritto Tributario, Mila, Cedam, 2013, pp. 219 y ss.; Dino JARACH, El hecho imponible, Buenos Aires, Abeledo Perrrot, 1971, pp. 51 y ss.

23643 Fernando PÉREz Royo, Derecho financiero y tributario. Parte general, Pamplona, Thomson Reuter, 2011; José Juan FerReIro, Instituciones de derecho tributario, op. cit.

44 Albert Hensel, Derecho tributario, Madrid, Marcial Pons, 2005. 
tras América Latina ha seguido las tendencias europeas en términos generales, si bien integrando elementos de originalidad. ${ }^{45}$

En Inglaterra y Estados Unidos existen diferentes énfasis de las categorias jurídicas teóricas, ${ }^{46}$ y hay preocupaciones específicas respecto de algunos aspectos de la OT, tales como su determinación judicial y administrativa y el problema de la elusión. La doctrina inglesa ha tratado de resolver el problema del cumplimiento mediante la tesis de que el sistema tributario se fundamenta en principios además de reglas. ${ }^{47}$

Sobre la RJT se han planteado diversas teorias, con muchos elementos distintivos. No obstante los esfuerzos de la doctrina, González García ${ }^{48}$ observa que el debate acerca de la relación jurídica obligacional se mantiene presente, y que las teorias hasta ahora sostenidas son insuficientes, inexactas y confusas. En general, la doctrina (por ejemplo, Ferreiro ${ }^{49}$ y Luchena ${ }^{50}$ ) distingue las siguientes tesis de la RJT (en vinculación con la teoría del tributo y de la potestad tributaria, como expresan González ${ }^{51}$ y Calvo $^{52}$ ):

a) El tributo como relación de poder o potestad de imperio del Estado que no conoce limites jurídicos, y en ese contexto el sujeto pasivo tiene una posición de sujeción. Define el tributo como "prestación coactiva" que tiene por objeto una obligación.

b El tributo como relación jurídica obligacional (a partir de la que nace la distinción entre el denominado "derecho tributario material” y el "derecho tributario

45 Ataliva y Barros CARVAlHo han optado por formular doctrinas originales. BarRos CARVALHO se esfuerza por construir su propio sistema analítico a partir de su regla matriz de incidencia (Paulo BARROs Carvalho, Curso de derecho tributario, Madrid, Marcial Pons, 2007); mientras Giuliani Fonrouge o Lugui han seguido las tesis europeas. C. Giuliani Fonrouge (Derecho Financiero, t. I, 10 edición, Buenos Aires, La Ley, p. 410) entiende que la "relación jurídico tributaria está integrada por los correlativos derechos y obligaciones emergentes del ejercicio del poder tributario, que alcanzan al titular de este, por una parte, y a los contribuyentes y terceros, por otro". Juan Carlos LugU, La obligación tributaria, Buenos Aires, Depalma, 1999.

46 John Tiley y Glen Loutzenhiser, Revenue Law, Oxford, Hart Publishing, 2012; Brian J. Arnold y Hugh J. Ault, Comparative Income Taxation, 3 ed., Aspen, Aspen Law, 2010.

47 Es posible destacar a: Judith Freedman, "Improving (no perfecting) tax legislation: rules and principles revisited”, British Tax Review 6 (2010), 717-736; Avori Jones, “Tax law: Rules or principles?”, Fiscal Studies 17 (3) (1996); Hans GriBnAu, "Legislative instrumentalism vs. legal principles in tax law", Rivista di Diritto Tributario Internazionale (International Tax Law Review) 3 (2012), pp. 9-42; Jhon Prebble, "Should tax legislation be written from principles and purpose point of view or a precise and detailed point of view?", British Tax Review 2 (1998), pp. 112-123; Hugh Ault y Victor Thurony, Comparative Tax Law, Kluwer Law International, The Hague, Kluwer Law International, 2003. Para similares objetivos se ha debatido acerca de la utilidad o posibilidad de establecer normativamente estándares de comportamiento como reglas para delimitar obligaciones (WeIsBACH, David A., "Formalism in the Tax Law", The University of Chicago Law Review 66 (3) (1999), pp. 860-886, en http:// www.jstor.org/stable/1600430.).

48 Eusebio GonZÁlez García, "La revisión de la relación jurídica tributaria obligacional: las corrientes procedimentalistas”, FORO, Revista de Derecho 9 (2008).

49 José Juan FerReIro, Instituciones de derecho tributario, op. cit.

50 Gracia Luchena, "La relación jurídico-tributaria. El hecho imponible", Derecho financiero y tributario: parte general, Miguel Ángel Collado Yurrita (dir.), 2013, pp. 255-268.

51 Eusebio GonZÁlez, "La enseñanza del derecho tributario”, Dikaion 9 (2000), pp. 37-54.

52 Rafael Calvo, Curso de derecho tributario, op. cit. 
formal”, como explica Quintana Ferrer), ${ }^{53}$ semejante a la existente en derecho privado, pero con la peculiaridad de que el contenido de la obligación viene determinado exclusivamente por la ley. En esta teoría toma relevancia la categoría de hecho imponible, como criterio legitimador del establecimiento del tributo. Aquí existen diferentes posturas, que se podrian agrupar como:

b.i.) Tesis estática (más orientada a la relación del Estado con el contribuyente) o teoría de la RJT compleja, defendida por Berliri y Giannini, ${ }^{54}$ conforme a la cual existe un haz de obligaciones, principales y accesorias, deberes y derechos. Al respecto, Quintana Ferrer ha sostenido que "esta tesis redujo a la unidad las diferentes relaciones tributarias, a la vez que situó a las relaciones derivadas de los deberes formales no pecuniarios en una posición subordinada respecto de la relación jurídica obligacional", y agrega que "insiste, por tanto, en los aspectos de las relaciones tributarias que son diferentes de la relación jurídica obligacional, con el fin de resaltar los aspectos procedimentales o formales con los que se encuentran los ciudadanos debido a la existencia de los tributos”. En esta postura, el tributo se concibe como función tributaria o procedimiento que engloba actos y situaciones cuyo fin es la obtención del ingreso. La crítica que se le efectúa es que sus defensores nunca pudieron delimitar esta obligación ni justificar la pervivencia de una obligación en caso de extinción de las otras.

53 Quintana explica: "Fruto de esta 'teoría de la relación jurídica obligacional', nace la distinción entre el denominado 'Derecho tributario material' y el 'Derecho tributario formal'. El primero tiene por objeto la mencionada relación jurídica obligacional, en términos acuñados por el derecho civil, consistente en el pago de una prestación pecuniaria en concepto de tributo, en la que la Administración ocupa la posición de acreedor y el particular la de deudor. Mientras que el segundo está compuesto por las normas que regulan los deberes que el contribuyente debe cumplir para hacer efectiva la obligación principal de pago y las potestades que, en sentido inverso, la ley reconoce a la Administración para hacerse efectivo este crédito. Por primera vez la doctrina alcanza el objetivo de distinguir los diferentes tipos de relaciones existentes con la aplicación de los tributos: la relación jurídica de carácter obligacional, objeto del 'Derecho tributario material', consistente en el pago de una suma de dinero en concepto de tributo, cuyo nacimiento se hizo depender del cumplimiento por parte del particular de un presupuesto de hecho descrito en la norma, conocido hoy en día como 'hecho imponible'; y el resto de deberes no pecuniarios, de hacer o de no hacer, que en la corriente que nos ocupa se agruparon en torno al acto administrativo de liquidación del tributo, que se concibió como acto de naturaleza declarativa de la obligación pecuniaria, y al resto de normas procedimentales tendentes al cobro de la mencionada obligación pecuniaria, en lo que vino a denominarse en conjunto el 'Derecho tributario formal”" (Esteban Quintana FerRer, "Hecho imponible”, Derecho financiero y tributario, en www.iustel.com. base datos Iustel, RI §910990, Portal Derecho, S.A. Iustel, 2002).

54 Para GianinNi, existen "entre el Estado y los contribuyentes derechos y deberes recíprocos, que forman el contenido de una relación especial: la relación jurídico-impositiva [...] la relación jurídicoimpositiva tiene un contenido complejo, pues de ella derivan, por un lado, poderes y derechos, así como obligaciones, de la autoridad financiera, a los que corresponden obligaciones, positivas y negativas, así como derechos, de las personas sometidas a su potestad, y de otra parte, con carácter más específico, el derecho del ente público a exigir la correlativa obligación del contribuyente de pagar la cantidad equivalente al importe del impuesto debido en cada caso" (Achille Donato GianNINI, Instituciones de derecho tributario, Madrid, Editorial de Derecho Financiero, trad. de Fernando Sainz de Bujanda, 1957, pp. 67-69). 
b.ii.) Tesis dinámica, o teoría del procedimiento de imposición, enfocada en los procedimientos de actuación de los órganos estatales para desarrollar dicha función (procedimientos de imposición). La debilidad de esta postura es que mezcla y confunde conceptos jurídicos elementales (confunde lo que el tributo es, con el cómo se aplica); siguen esta postura Maffezzoni, Micheli, Fantozzi, Fedele. ${ }^{55}$

b.iii.)Tesis conciliadora, según la cual, el tributo se estructura a partir del esquema básico de la obligación tomado del derecho privado; el sujeto acreedor de la OT no es titular de un concreto derecho subjetivo de cobro sino una potestad administrativa (inspectora, liquidatoria, recaudatoria y revisora), que debe ser ejercitada al servicio de los intereses generales; no persigue el simple interés en el crédito tributario sino un interés público (de carácter constitucional).

Por otro lado, existe otra disputa entre las diferentes teorias respecto del nacimiento de la OT y de la naturaleza de la función del acto administrativo de determinación de la OT (si es constitutivo o es declarativo de ella, en relación con la función de la ley), que lleva a la denominación de teorías constitutivas y teorías declarativas (desde la segunda mitad del siglo pasado surgen las teorías neoconstitutivas y procedimentalistas). Autores como Russo ${ }^{56}$ las expone, y analiza sus puntos débiles y fuertes. ${ }^{57}$ Este autor rescata la distinción entre tributos liquidables (deben ser determinados por un acto administrativo, con accertamento; y en ellos distingue una doble fase: estática y dinámica) y autoliquidables (senza accertamento, pueden ser determinados por el propio contribuyente), para decidir sobre su preferencia frente a una de ambas posturas, aunque este autor se inclina por la tesis declarativa, cumplido el presupuesto de hecho representativo de capacidad contributiva. ${ }^{58}$

55 Gorospe indica que algunos distinguen además una teoría de la función tributaria, entendida ella como poder-deber del Estado para desarrollar la actividad tributaria, para obtener recursos mediante medios coactivos. Refiriéndose a esta teoría, Guintana FerRer señala que "se presenta como una tesis dinámica que, a diferencia de las tesis estáticas del fenómeno tributario que se habian sucedido hasta ese momento, centra su atención en la serie de actos sucesivos y de situaciones jurídicas que conducen al pago del tributo".

56 Pasquale Russo, La obligación tributaria. Tratado de derecho tributario, Andrea Amatucci (dir.), Bogotá, Temis, 2001, pp. 17-43.

57 Sobre la base de la doctrina italiana, Pérez De Ayala distingue entre el deber de pagar que nace con el cumplimiento del hecho imponible, de la obligación de pagar que nace con el acto liquidatorio. Hay quienes defienden que dicha obligación nace desde la realización del hecho imponible; otros, desde la liquidación. Solo con el acto liquidatorio surgirá la tutela jurídica del crédito para la Administración, un derecho subjetivo. Antes, solo existe una situación de poder para la Administración. Para la otra perspectiva, todas las situaciones subjetivas de contenido patrimonial nacidas en el ámbito tributario son reconducibles a la categoría de obligación. El acto liquidatorio hace líquida y exigible la obligación, ya nacida con la realización del hecho imponible (José Luis Pérez De Ayala, Dinámica de la relación jurídica tributaria en el derecho español, Madrid, Dykinson, 1997, pp. 33-39).

58 Martínez Lago sostiene que esta discusión no se da en el derecho positivo español, ya que la OT nace con la sola realización del hecho imponible (Miguel Ángel Martínez Lago, "El hecho imponible", Derecho financiero y tributario, en www.iustel.com. base datos Iustel, RI §911733, Portal Derecho, S.A. Iustel). "Al ser la obligación tributaria una obligación ex lege, la misma surge cuando se realiza el hecho previsto, tipificado por la norma a tal fin. Se trata de un hecho jurídico, ya que de su realización derivan efectos juridicos". 
Para Ferreiro, las teorias que suponen una relación de poder del Estado sobre los contribuyentes entienden el tributo como prestación coactiva, lo que es contrario al actual Estado de democrático de derecho. ${ }^{59}$ Este autor comparte la teoría que entiende el tributo como una obligación y lo vincula con la teoría de obligación jurídica general y coherentemente con el resto del ordenamiento jurídico, y con la propia idea de Estado democrático de derecho. Esto último se refleja en que mediante este expediente incorpora el principio de separación de poderes y el de personificación del Estado, y coloca al ciudadano y al Estado en un plano de relación horizontal en cuanto ambos son sujetos de derecho, sometidos a la ley. ${ }^{60}$ Para este autor, dicha perspectiva otorga coherencia al ordenamiento tributario, e integra el sistema tributario con el resto del sistema jurídico. Añade que la OT surge de la realización del hecho imponible y, por ello, el contribuyente debe satisfacer la prestación debida. De ahí que la RJT implica a la OT. Distingue entre obligación principal, y obligaciones accesorias y formales. ${ }^{61}$

Para la doctrina, todas las obligaciones tributarias se vinculan a la obligación principal (de pago), incluidas la de los responsables tributarios y las obligaciones a cuenta (existe una relación de subsidiariedad). En palabras de Ferreiro: "esta intima relación con la OT principal deriva de que todas ellas satisfacen el mismo y único interés del acreedor: el cobro del tributo debido". ${ }^{62}$ Junto a las obligaciones subsidiarias, surgen obligaciones accesorias a la principal (obligaciones de pago por intereses de demora, por recargos, por sanciones por falta de pago, y obligaciones de pago entre particulares derivadas del tributo), enfatizando que:

... el derecho tributario no disciplina solo la obligación de pago en que el tributo consiste. Regula muchas otras situaciones, vinculos y relaciones encaminadas todas ellas en su normativa y dentro de un orden constitucional democrático como el nuestro a dos fines esenciales: la efectiva aplicación de los tributos conforme al principio constitucional de capacidad económica y el sometimiento del poder - también del poder tributario- y de su ejercicio a la ley y al derecho. ${ }^{63}$

Para Ferreiro, la doctrina prestó demasiada atención al análisis de la OT y descuidó el estudio de los procedimientos tributarios. Ahora, junto con exigirse una interpretación sistemática de la normativa tributaria, debe considerarse la distinción entre derecho tributario sustancial o material (derecho tributario de obligaciones) y adjetivo o formal (instrumental a la efectiva aplicación del tributo, por tanto, no priva ni atribuye a nadie un bien o un derecho). ${ }^{64}$ De ahí se comprende la existen-

59 Una perspectiva como esta es modulada por P. MAssone (Principios de derecho tributario, op. cit., p. 791), quien defiende la idea de tributo como obligación coactiva.

$240 \quad 61 \quad$ Ibid., p. 177.

62 Ibid., p. 179.

63 Ibid., p. 173.

64 Ibid., p. 179. 
cia de obligaciones formales, las que no tienen un fin en sí mismas, sino la efectiva aplicación del tributo. ${ }^{65}$

\section{NUESTRA PERSPECTIVA DE LA RELACIÓN JURÍdICA TRIBUTARIA Y LA OBLIGACIÓN TRIBUTARIA}

Hemos manifestado que nuestro objetivo es el de poner las doctrinas actuales en una cierta perspectiva, un cierto prisma través del cual observar las instituciones y categorias a que este artículo se refiere. Este consiste en centrar el problema de la relación jurídica tributaria en el ciudadano (como sujeto de derechos y deberes), como categoría jurídico-política prelegislativa a la cual se ordena la potestad tributaria, enfatizando el deber de contribuir como categoría jurídica central del sistema tributario, desde la cual este se construye como estatuto jurídico que vincula a personas y órganos estatales, en una relación jurídica estatutaria. Es el ciudadano el miembro de la comunidad politica, titular del poder del Estado y de la hacienda pública.

Este prisma, al menos, busca mostrar que una cierta comprensión de la potestad tributaria se alinea con un determinado concepto de tributo y de RJT (y de OT). La atenuación de la importancia de la potestad tributaria y la mayor presencia de la categoría "deber constitucional de contribuir a los gastos públicos", tienen una fundamentación (énfasis en el ciudadano más que en el poder estatal) y una consecuencia en la comprensión de la RJT (y de la OT).

Trataremos de explicar nuestra perspectiva a través del tratamiento de seis tópicos:

a) La complementación de la categoría de hecho gravado (entre otras), como partícula singular que fundamenta la RJT y la OT, con la categoría de relación jurídica estatutaria.

b) El estatuto tributario como producto principal del ejercicio de la potestad tributaria (vinculada a la ciudadanía y al deber de contribuir a los derechos fundamentales). ${ }^{66}$

c) La función del estatuto tributario frente a la tesis de OT como obligación legal.

d) La importancia de los procedimientos en la configuración de las obligaciones tributarias.

65 Massone distingue entre obligación patrimonial (obligación de pago, con el correspondiente derecho de la Administración) y deberes administrativos del contribuyente (obligaciones formales, con la correspondiente potestad de la Administración). MASsone explica que los deberes formales o accesorios (BARRos CARVALHo) o de contorno (AlEssi) tienen por objeto facilitar el conocimiento, control y recaudación de las sumas debidas como tributos (Pedro MAssone, Principios de derecho tributario, op. cit., pp. 771-775).

66 Como sostiene Scalinci, tanto el carácter como el contenido del derecho tributario debe ser considerado como derecho de ciudadanía. Costantino Scalinci, Il Tributo Senza Soggetto, Italia, Cedam, 2011 , p. 51. 
e) La estructura normativa del estatuto jurídico tributario, y la necesidad de otorgar unidad, coherencia y sistematicidad al ordenamiento jurídico tributario mediante principios.

f) La concepción de potestad tributaria como instrumento de ciudadanía, y el estatuto tributario como su producto más relevante a partir del deber de contribuir a los gastos públicos con garantía de los derechos fundamentales, en el contexto del Estado constitucional y democrático de derecho.

a) Como se ha mostrado, la OT es entendida como obligación vinculada al cumplimiento del hecho imponible; y el devengamiento, como el momento en que nace la OT, sujeta al plazo de exigibilidad. Es decir, la OT es comprendida en términos semejantes a la obligación de derecho privado, no obstante sostenerse de modo expreso por la doctrina que se trata de una obligación de derecho público. Del modo expuesto por la doctrina, la OT parece describirse como una obligación de actos y hechos concretos: se debe algo porque (y solo porque) se efectúa una acción o actividad determinada o sucede un hecho determinado, descrito minuciosamente en la ley ${ }^{67}$ Esta tesis de la OT, sustentada en el hecho o acto singular llevado a cabo por el contribuyente, no muestra suficientemente bien el carácter de la vinculación del obligado tributario con el sistema jurídico tributario en su conjunto. ${ }^{68}$ Desde nuestra perspectiva, no considera la realidad de la relación del obligado tributario con el Estado, cual es una vinculación de carácter estatutario, ${ }^{69}$ que es lo propio de una obligación de derecho público configurada sobre el deber de contribuir.

A nuestro juicio, y sin desmerecer en absoluto la categoria del "hecho imponible" (y tampoco otras que han sido tan minuciosamente perfiladas por la doctrina en tantas décadas), resulta posible apreciar que ella se trata de una hipótesis normativa, un elemento legal dentro de muchos otros que determinan el nacimien-

67 Estas teorías suelen comprender la OT como aquella referida directamente a la aplicación del tributo, al pago de una suma de dinero. Por ello se enfatizan en primer término los elementos del tributo, esto es, el hecho generador del mismo (hecho gravado); la distinción entre obligaciones principal, accesorias y formales; los diferentes supuestos de obligados tributarios (y al o los posibles sujetos activos); los procesos y elementos de cuantificación (determinación de base imponible); mecanismos de exclusión del gravamen, supuestos de exenciones o de no sujeciones, totales o parciales; beneficios o recargos bajo determinados supuestos en que se encuentre o realice el contribuyente, etc.; alícuotas o tipos de gravamen; a sus modos de extinción; etc. Para estas teorías los otros elementos relevantes de la obligación, los actos de acertamiento (del contribuyente o de la Administración), son solo actos declarativos de la obligación legal, generada al momento de producirse el hecho imponible, que implica el devengo del tributo (solo sujeto a un plazo para su exigibilidad y cumplimiento). Todos los actos y procedimientos administrativos (de fiscalización de determinación, etc.), o judiciales tienen por objeto la "actuación" de la ley tributaria. Las demás actividades institucionales tienen por objeto resguardar el cumplimiento integro de la ley y el deber del contribuyente de cumplir con su principal, que se muestra como la obligación por antonomasia (sanciones administrativas y penales frente a los casos en los que la Administración Tributaria estima que ha existido un incumplimiento por parte del contribuyente, los procedimientos judiciales tributarios de diversa naturaleza, etc.).

24268 José Luis Pérez De Ayala et al., Fundamentos de derecho tributario, op. cit., p. 41.

69 No nos referimos a la idea de estatuto del contribuyente, o no solo a ello; obviamente existe. Nuestra comprensión es más amplia y se refiere a la relación del Estado y sus organismos con el ciudadano. Francesco Tesauro, Compendio di diritto tributario, op. cit., p. 10. 
to de la OT. ${ }^{70}$ Dado que son muchas las normas que concurren (hay un juego de normas), defendemos la existencia de un estatutojurídico más que de norma legal particular (que contiene un hecho gravado) como aquella que vincula al obligado tributario (usando este término en sentido general).

Que el vínculo de los habitantes de un Estado sea estatutario implica que principalmente se sujetan de modo completo y permanente (juridicamente hablando, por un tiempo prolongado de acuerdo con las reglas específicas establecidas en cada sistema jurídico) a un sistema tributario, y no (o no solo) a través de actos o hechos particulares. Por ello, puede considerarse al sistema tributario como un estatuto jurídico de contenido complejo de carácter eminentemente legal, que determina la posición jurídica, y las posibilidades y condiciones de actuación de los ciudadanos y de los órganos del Estado, y que se encuentra compuesto por reglas, principios jurídicos y valores, derechos y deberes, relaciones jurídicas, facultades y potestades, funciones y responsabilidades, procedimientos, órganos, instituciones, etc. ${ }^{71}$ De este modo, la persona (aunque sea sujeto de derecho privado), en el ámbito del derecho tributario se encuentra sujeta a un régimen de derecho público con independencia de que deba o no pagar un impuesto específico, a un estatuto cuyo contenido no depende de su voluntad, y nada de lo que haga con incidencia tributaria puede ser opaco ni oculto. Desde esta perspectiva, es posible encontrar

70 No me refiero de modo exacto a la tesis planteada por el tributarista brasileño Gerardo Ataliva, respecto de la "hipótesis de incidencia" como aquella referida a la descripción abstracta de la ley del hecho gravado y demás elementos de la obligación tributaria (Gerardo Atalva, La hipótesis de incidencia, Lima, ARA, trad. por Jorge Bravo CuccI, 2012, pp. 66 y ss.).

71 Que el sistema tributario creado en virtud de la potestad tributaria sea estatutario (si se quiere, el derecho tributario constituye un derecho estatutario), puede ser explicado desde las palabras de RodRíGuez GARCIA: "Derecho estatutario vendría a ser aquel derecho que se dirige con carácter especifico a la regulación de determinados sujetos, o cualidades jurídicas que posean, o puedan poseer, dichos sujetos; proporcionando a dichos sujetos la protección jurídica que sea precisa y necesaria, en relación con los rasgos singulares de tales sujetos y las funciones sociales que asumen". Este mismo autor cita otras definiciones: el término estatuto se definiría como "un conjunto de reglas (auténticas normas jurídicas o, simplemente cláusulas de un convenio) que establecen la configuración básica de un sujeto, de una categoría de sujetos, o de una cualidad jurídica propia de ellos" (L. Morell Ocaña, Curso de derecho administrativo, t. 1, Pamplona, Aranzadi, 1998, pp. 53-54); "Derecho estatutario sería aquel sistema de normas jurídicas, aquel ordenamiento jurídico, que sería imperativo, no por su propia voluntad, sino porque tal fuerza imperativa le vendría conferida por un ordenamiento distinto y superior. En consecuencia, el ordenamiento jurídico estatutario carecería de imperatividad originaria, aunque sí la tendría derivada” (L. C. IBAN, Derecho canónico y ciencia jurídica, Madrid, Servicio de Publicaciones de la Facultad de Derecho de la UCM, 1984, p. 154). José Antonio Rodríguez García, "El derecho canónico como derecho estatutario en el ordenamiento jurídico español”, Ius canonicum 39 (1) (1999). MARTin MAteo explica: “Lo anteriormente expuesto vale también para la conceptuación del derecho administrativo como derecho estatutario, como derecho común de los sujetos administrativos, de la personalidad interior del Estado, en definitiva, porque conjugando la naturaleza singular de las personas a que va destinado y la peculiaridad de los intereses perseguidos, se comprende perfectamente su carácter de Ordenamiento común para la función pública administrativa. Así se percibe con nitidez sus posibilidades autointegradoras, su articulación en torno a un tramado de principios generales que le son propios y la vitalidad con que realiza la adecuación y climatización en su propio terreno de instituciones provenientes de otros derechos, que una vez trasplantados al derecho administrativo, son inmediatamente impregnados de nueva sustancia. La presencia de la Administración da, en efecto, un sentido distinto a cuantas actuaciones realiza, no importa con qué instrumentos, aunque en unos casos con mayor o menor intensidad y radicalidad que en otros" (Ramón MARTín MAteo, "La sustantividad del derecho administrativo”, Revista de administración pública (53) (1967), pp. 35-72). 
un claro fundamento del deber de informar del contribuyente, o de la potestad de la Administración para recalificar los actos del contribuyente, por ejemplo, entre otras consecuencias. ${ }^{72}$

b) Conforme a nuestra perspectiva, la potestad tributaria no es sino la potestad de los órganos democráticos (representativos del ciudadano) de configurar el sistema jurídico con apego a la Constitución, de crear esta red o sistema que vincula al órgano público y al ciudadano denominado estatuto tributario, que concreta el deber constitucional de contribuir con plena consideración de todos los derechos y las garantías del obligado tributario, por lo que ambos sujetos son activos y pasivos de diferentes obligaciones y deberes, derechos y potestades.

Pero la potestad tributaria no tiene la funcionalidad directa de crear la obligación tributaria o el crédito tributario. Obviamente, en virtud de la aplicación del sistema tributario puede surgir la obligación material o de pago, por ello es contingente, no es necesaria. La creación del sistema tributario sí es consecuencia necesaria de la existencia de la potestad tributaria, y no es contingente, dado que deriva de la formulación de un estatuto jurídico de derecho público al que se sujeta el contribuyente. De ese modo, el derecho extrae de la regulación del derecho común una serie de actos jurídicos y relaciones jurídicas, y las sujeta enteramente a un determinado estatuto que rige todos sus aspectos, y que llama al resto del ordenamiento en los casos en que este debe suplir sus vacios. El derecho tributario es un derecho estatutario enteramente de derecho público, de modo semejante a como lo es el derecho administrativo, ${ }^{73}$ e incluso opera publificando las actuaciones y las relaciones privadas.

72 La relación jurídica de derecho público o relación jurídica pública, es una categoría amplia que incluye una serie de figuras, de distintas configuraciones jurídicas (S. Ponce De León, "El contrato de concesión de obra pública en la legislación chilena”, Revista de Derecho Público 79 (2013), p. 115). No obstante lo anterior, dice relación con la idea de intereses generales, fines públicos y colectivos, y razones de orden público, desigualdad de intereses (además de posición soberana o imperium) que fundamentan, y poderes planos de superioridad de la Administración, de régimen de Derecho Administrativo, de regulación legal, de normas predominantemente imperativas. Sobre el punto, SORIANo explica que tradicionalmente "[l]a Administración pública se ha venido sistemáticamente negando a aceptar al ciudadano como el otro extremo de una relación jurídica, simplemente porque era su objeto. Era el objeto en términos generales de un acto administrativo". Este autor añade que el análisis de la relación jurídica pública pasa por el análisis de los sujetos, objeto y actividad de tal relación de derecho y "más concretamente dentro del objeto, por un estudio tanto de la materia sobre la que aquella recae, así como sobre el contenido, es decir, los derechos y obligaciones" (José SoRIano, "Evolución del concepto 'relación jurídica' en su aplicación al derecho público", Revista de Administración Pública 90 (1979), p. 50). Para Soriano es la definición estatutaria del derecho administrativo lo que define el ámbito jurídico público. "Consideramos que la definición estatutaria del derecho administrativo encuentra en la convulsiva legislación de estos momentos un test adecuado para verificar la solidez de su construcción y consecuentemente aceptar dicha tesis como un genuino logro científico que no encuentra su apoyo, más o menos circunstancial, en la afortunada redacción de unas normas, sino que está obtenida de la misma observación histórica, razón esta que le presta su adaptabilidad y consecuente capacidad de cambio, aceptando desprenderse de aquello que pueda resultar producto de un momento para pasar a elevarse dogmáticamente a la categoría; a la misma explicación estructural del fenómeno jurídico" (José Soriano, "Evolución del

24473 Como lo explica PARADA: "Hay normas, pues, destinadas a los sujetos jurídicos en general y otras que presuponen su afectación o destino en todo caso a unos determinados sujetos. Ocurre lo mismo con el derecho mercantil, cuyas normas están destinadas a determinados sujetos en tanto que 
c) Otro aspecto, es la evaluación de la idea ortodoxa de actuación directa de la ley en la OT, en la que la ley tributaria tiene la forma de reglas.

Comúnmente, se sostiene por la doctrina que la OT nace por ley (carácter ex lege), la que debe ser aplicada de modo estricto por los órganos administrativos y judiciales, mediante actos administrativos o judiciales que permitan actuar a la ley mediante una serie de estrictas directrices interpretativas ${ }^{74}$ que es la que impone la obligación legal al contribuyente, imperativa, indisponible, innegociable. ${ }^{75}$ A su vez, bajo este esquema la ley tributaria es formulada mediante reglas muy descriptivas y detallistas, que apelan a la seguridad juridica.

Como consecuencia de dicha comprensión del principio de reserva de ley y de la fórmula de la descripción estricta de la ley tributaria, se privilegia la interpretación silogística, que conduce a un carácter reglamentario de la ley, con sobreabundamiento del detalle técnico y casuístico, con pretensiones de máxima exhaustividad. No obstante lo anterior, el contribuyente bien asesorado siempre encuentra intersticios que le permiten planificar fiscalmente. Para paliar este interminable e infructuoso camino, el legislador se ve en la necesidad de otorgar más y más funciones y potestades discrecionales o ampliamente discrecionales ${ }^{76}$ a la Administración Tributaria, incluso con limitaciones legales al control jurisdiccional de ellas (bajo el pretexto de que la Administración solo aplica la ley). ${ }^{77}$ Para apoyar estas

comerciantes, o con el derecho laboral, concebido como un derecho por y para los trabajadores, $\mathrm{y}$, en fin, con el derecho administrativo como derecho de las administraciones públicas, porque las normas de unos y otros presuponen que en la clase de relaciones que regulan intervendrán necesariamente esas categorias de sujetos. En este sentido, el derecho administrativo es un derecho estatutario, el derecho de las administraciones publicas, como lo ha denominado García de Enterria” (Ramón PARADA, Concepto y fuentes del derecho administrativo, 2 ed., Madrid, Marcial Pons, 2012, p. 12).

74 Incluso se ha defendido la existencia de un principio de tipicidad tributaria. PALAo TABOADA (La aplicación de las normas tributarias y la elusión fiscal, Madrid, Lex Nova, 2009, p. 63) se limita al uso de la analogía en la creación de las obligaciones tributarias, y establece una serie de otras condiciones (M. Siota, Analogia e interpretación en el derecho tributario, Madrid, Marcial Pons, 2010).

75 Fernando Pérez Royo, Derecho financiero y tributario, parte general, op. cit, p. 140.

76 La fórmula que en Chile ha servido para limitar los efectos de estas potestades sobre el contribuyente ha sido la defensa de un "principio de tipicidad" basado en el "principio de legalidad" (en Chile entendido como una mezcla del principio de legalidad administrativa y de reserva de ley)", lo que ha permitido circunscribir la obligación de contribuir solo a las exigencias estricta y expresamente declaradas en la ley (V. M. Avilés, Legalidad tributaria y mecanismos antielusión, Santiago, Jurídica, 2014; MEZa e IвACETA, El principio constitucional de legalidad en materia tributaria, Cuadernos del Tribunal Constitucional 37, Santiago, 2007). A pesar de ello, se han acentuado las limitaciones a los derechos de los contribuyentes, de modo más allá de lo razonable, a través de una práctica que valida las potestades no delimitadas de la Administración Tributaria en la interpretación y aplicación del Código Tributario y de la fiscalización del cumplimiento de las obligaciones tributarias del contribuyente (I. Melo et al., La facultad interpretativa del Servicio de Impuestos Internos y los cambios de criterio, Santiago, Thomson Reuters, 2013). La configuración legal actual de las potestades tributarias, en la Administración Tributaria, distan de las concepciones generales del derecho administrativo chileno más allá de lo que resulta razonable, aún cuando se considere la modulación necesaria para la exigencia del tributo (ZuRITA, El acto administrativo tributario, Libromar, 2013; PANTOJA, Derecho Administrativo: 150 años de doctrina, Santiago, Editorial Jurídica de Chile, 2009).

77 El Código Tributario chileno intenta esto mediante fórmulas tales como la asignación de facultades discrecionales exclusivas, como por ejemplo, "juicio exclusivo", presentes en los artículos 16, 17, 
orientaciones, y evitar el incumplimiento del deudor tributario (y en esta perspectiva el contribuyente siempre lo es) mediante su conducta elusiva en el ejercicio de la autonomía de la voluntad, ${ }^{78}$ se recurre a toda clase de técnicas legislativas, como: el establecimiento de ficciones y presunciones; imposición de condiciones o de limitaciones a la actividad de los particulares; extensión o sustitución de responsabilidad tributaria; normas antiabuso especiales y generales, incluidas las referidas a abuso del derecho, fraude de ley; ${ }^{79}$ limitaciones a los derechos procesales, limitación en los medios de prueba y oportunidad para presentarlos; se establecen toda clase de mecanismos inhibitorios del ejercicio de la acción o de la sustentación del proceso judicial por parte del contribuyente; se superpuebla la ley de obligaciones formales y de información; incorporación de elementos valorativos en las normas tributarias; altas multas, intereses y penas; no se permite transar en caso de conflictos; etc.

Pero aún con ello, el derecho tributario parece fracasar pues no se logra concretar una tributación del contribuyente de acuerdo con su capacidad económica (desde una perspectiva de su valor de justicia tributaria predicado en el discurso jurídico general); se generan en la práctica constantes contradicciones en la aplicación de la norma legal por parte de las administraciones tributarias, y de toda clase de tribunales y jerarquias de ellos, que a cada paso parecen cambiar la comprensión, el carácter y sentido de las normas tributarias en los casos concretos, es decir, de las OT. ${ }^{80} \mathrm{Al}$ contrario, considerar la vinculación del obligado tributario al sistema de modo estatutario, permite solucionar estos problemas, dado que refleja de mejor manera el modo concreto en el cual el obligado se encuentra sujeto, y las condiciones de su posición jurídica en el sistema como asimismo de la autoridad tributaria.

d) Otro aspecto que queremos destacar se refiere a la importancia que otorgamos a los procedimientos administrativos y judiciales en la configuración de las obligaciones tributarias. En general, las tesis actuales presentan una comprensión estática de la OT que no pone de relieve la dinámica de los actos y procedimientos institucionales de configuración de la misma, ${ }^{81}$ y tampoco considera las exigencias y los condicionamientos del sistema tributario en los términos que actualmente

21, 23, 31, 60 ter, 75, 87, 88, 106, 128; o la Ley sobre Impuesto a la Renta en sus artículos 31, $41,41 \mathrm{E}, 68,74$.

78 H. TAVEIRA ToRres, Derecho tributario y Derecho privado. Autonomía privada, simulación y elusión tributaria, Buenos Aires, Marcial Pons, 2008.

79 Gloria MARÍn, La relevancia jurídica de la motivación fiscal. Influencia del business purpose en el ordenamiento tributario español, Madrid, Dykinson, 2009.

80 Sobre las contradicciones entre órganos judiciales y administrativos es posible citar, entre otros análisis: Patricio MAsBernat, "Principios constitucionales tributarios en la sentencia Roles № 139909-INA y № 1469-09-INA, acumulados, del Tribunal Constitucional, de 4 de noviembre de 2010: Referencia al caso 'Gerhard Schweinitz con SII', Corte de Apelaciones de Concepción, Rol 8002010, de 1 de diciembre de 2010”, Estudios constitucionales 9 (2) (2011), pp. 753-770. José Luis Pérez De Ayala, Fundamentos de derecho tributario, op. cit. 
exige el Estado constitucional y democrático de derecho, ${ }^{82}$ es decir, de acuerdo con la comprensión del sujeto pasivo de la obligación tributaria como ciudadano ${ }^{83}$ y persona (sujeto de derechos).

Obviamente, es la ley formal (principio de autoimposición) la forma de establecer la RJT en sus elementos fundamentales en términos de "estatuto" (no establece, a nuestro juicio, los elementos esenciales del tributo, ya que estimamos que el "tributo" no es un término intercambiable por el de OT), pero de ello no es posible seguir que el juez o la Administración solo sean el instrumento de actuación de la ley o de la voluntad del legislador (esa afirmación es dificil de aceptar en el marco del desarrollo actual de la teoría general el derecho). ${ }^{84}$ Tanto los órganos administrativos como judiciales deciden entre opciones, incluso a veces no optan por las más plausibles jurídicamente, y todas esas decisiones (a veces no suficientemente fundadas, erradas o contradictorias) ${ }^{85}$ valen como normas jurídicas secundarias, porque son parte del sistema juridico tributario y en cuanto tal configuran de manera concreta la obligación del contribuyente. Lo único que es posible solicitar, tanto a nivel teórico como legal, es que el órgano decisor fundamente adecuadamente su decisión para asegurar su corrección o racionalidad, ${ }^{86}$ pero el contenido de ella puede ser variable por razones de aplicación de ley sustancial

82 Juan Manuel BARguero, La función del tributo en el Estado social y democrático de Derecho, Madrid, CEPC, 2002, p. 49.

83 "En este sentido, el pago de impuestos y la recepción por ello de una serie de servicios públicos y prestaciones sociales se erigen como las bases del "contrato fiscal' entre el Estado y los contribuyentes ciudadanos" (MARIA GoEnAGA, "Elementos principales de la cultura fiscal en América Latina”, Documentos de Trabajo, Instituto de Estudios Latinoamericanos 42 (2012), p. 41).

84 Hoy en día, se entiende que la tesis de la claridad de los textos jurídicos constituye una ficción (aún desde una perspectiva ecléctica), y en cuanto tal estimamos dificil levantar una teoria general del derecho tributario sobre dicha tesis (Ricardo Guastini, Interpretar y Argumentar, Madrid, Centro de Estudios Políticos y Constitucionales, 2014, p. 353).

85 De acuerdo con las teorías estándares de la OT, por decirlo de algún modo, se entiende que la Administración Tributaria o el juez son la boca muda de la ley (parafraseando a Montesquieu), por lo que existiria una manera correcta de aplicarla, de modo que si diversos órganos se encuentran en discrepancia, sería el de rango más alto el infalible (la OT nace de la ley). El problema es que no es sustentable dicho argumento, porque los órganos no aplican directamente la ley o no aplican solo la ley, o no aplican solo la ley sustantiva (pues también incide la legislación referida a los procedimientos). En efecto, se aplican muchas leyes frente a un caso y las decisiones judiciales o administrativas obedecen a múltiples razones o causas (más aún en los llamados casos difíciles). Por ejemplo, puede ser el órgano inferior el que aplique de modo (más) correcto (o más plausible) la ley. Entonces, el argumento no es de corrección sino solo de autoridad: la decisión del órgano institucionalmente vale más, no porque se aplique la ley sino porque ese órgano tiene institucionalmente poder para imponer su postura en el sistema jurídico. En dichos términos, nos encontramos frente a una decisión interpretativa y no frente a la forma correcta de aplicar la ley. Entonces, la aplicación de la ley tributaria dice relación con diferentes interpretaciones que compiten, con lo que el contenido de la OT (derivado de la aplicación de la ley tributaria) no es necesario sino contingente (se fundamenta más en la decisión del órgano que aplica la ley que en el propio contenido de la ley, dado que la aplicación de la norma incluye múltiples elementos de decisión, muchos entre ellos, las pruebas presentadas y exclusión o inclusión de ellas y su valoración, y un largo número de otras decisiones que adopta el órgano aplicador de la ley). La función juez, en el Estado constitucional de derecho, se encuentra en decidir y argumentar, y no en demostrar. Orlando PARADA VACA, "El juez en el Estado Constitucional”, en Revista Iuris Tantum 13 (2012), pp. 7-9. Javier Aguirre, Pedro García y Ana PABÓn, “¿Argumentación o demostración en la decisión judicial? Una mirada en el Estado constitucional”, en Revista de derecho 32 (1-29) (2009), p. 6.

86 Lorena RAMíREz Ludena, "Verdad y corrección en la interpretación jurídica", Revista de derecho (Valdivia) 28 (1) (2015), pp. 9-31. 
como de ley procesal, administrativa o judicial (dado que en general no existe una única respuesta correcta, solo unas opciones más plausibles que otras). Esto trae consecuencias, por ejemplo, la validez de negociación sobre la concreta obligación de un contribuyente, bajo reglas de buena administración tributaria tales como la adecuada tutela del interés fiscal, y la fundamentación racional de la decisión de la Administración.

e) Otro aspecto por destacar es el análisis de la estructura normativa del estatuto jurídico tributario, y la necesidad de otorgar unidad, coherencia y sistematicidad al ordenamiento jurídico tributario, mediante principios. ${ }^{87}$

A nuestro juicio, no se observa en forma clara el modo en que las teorias mayoritarias otorgan un sustento suficiente al legislador para crear un sistema tributario dotado de notas de unidad, coherencia y sistematicidad, dado que su pretensión es fundar la obligación únicamente en reglas, y en hechos y actos singulares. La vía a los principios no reduce los niveles de certeza del sistema, ${ }^{88}$ ya que las técnicas de aplicación son muy estrictas. ${ }^{89}$

Hoy en día, la teoría general del derecho considera que el sistema jurídico (incluido el de naturaleza tributaria) se conforma de reglas pero también de principios $^{90}$ y valores, ${ }^{91}$ y que no existe una única solución correcta frente a un caso, especialmente en aquellos difíciles o complejos. Son los principios los que otorgan sistematicidad, unidad y coherencia al sistema jurídico, y capturan las fisuras que dejan las reglas, cuales son, los ilícitos atípicos, tan propios del ámbito de la tributación. Ahora, estimamos que la aplicación de reglas y de principios resulta mejor expresada mediante la idea de estatuto jurídico, que abre asimismo relevancia al proceso de aplicación del derecho y la necesidad de la fundamentación técnica y racional de las decisiones de los órganos encargados de tomar decisiones institucionales. ${ }^{92}$

87 Óscar Buenaga Ceballos, Metodología del razonamiento jurídico-práctico. Elementos para una teoría objetiva de la argumentación jurídica, Madrid, Dykinson, 2016, pp. 161-180.

88 Hay formas de dar lugar a la certeza a través del uso de principios, sobre todo dada la exigencia de justificación que la aplicación de estos requieren (J. BRArthwArTe, "Making tax law more certain: A theory", Australian Business Law Journal 31 (2) (2003), pp. 72-80).

89 Humberto Ávila, Teoría de los principios, Madrid, Marcial Pons, 2011, pp. 121 y ss.

90 Ricardo Guastin, Interpretar y argumentar, Madrid, Centro de Estudios Constitucionales, 2014, pp. 183 y ss.

91 Sobre la fundamental necesidad de entender, interpretar y crear el sistema jurídico tributario sobre la base de valores y principios, y de configurarlo legalmente sobre la base de principios, se ha referido originalmente Jones (“Tax law: Rules or principles?", op. cit.), enfatizado por Gribnau (“Legislative instrumentalism vs. legal principles in tax law", op. cit.), desde una perspectiva interpretativa general; PrebBle ("Should tax legislation be written from principles and purpose point of view or a precise and detailed point of view?", op. cit.), desde una perspectiva de su aplicación judicial; FreEdman ("Improving (no perfecting) tax legislation: rules and principles revisited”, op. cit.) desde la perspectiva de la configuración legislativa.

92 La coherencia interna del sistema constituye una exigencia del ordenamiento jurídico en general y del tributario en particular. GiovaninNi sostiene que la interpretación constitucional sistemática reduce las antinomias del sistema $(2014,12)$, donde los principios de solidaridad e igualdad elementos para tales objetivos (p. 12), y consideran, asimismo, la reserva de ley como garantía normativa (p. 17) (Alessandro Giovannini, Il Diritto tributario per principi, Milano, Giuffre, 2014). 
f) La potestad tributaria se debiera concebir como un deber-poder jurídico finalizado, es decir, que nace y se configura de acuerdo a derecho y se ejerce de acuerdo a derecho, ${ }^{93}$ que constituye un instrumento de ejercicio de la ciudadanía. Su específica función es la de otorgar competencia al Estado para configurar un sistema tributario de carácter estatutario que dé cuenta de la relación jurídica tributaria de carácter estatutaria, a partir del deber de contribuir a los gastos públicos con pleno respeto de los derechos fundamentales, ${ }^{94}$ en el contexto del Estado constitucional y democrático de derecho. La principal consecuencia de la instauración de un sistema tributario estatutario es una vinculación a este de los órganos del Estado, la Administración, los Tribunales, los obligados tributarios y los contribuyentes. ${ }^{95}$

Ahora, es posible concebir que todos los sujetos vinculados al sistema tributario, en cuanto estatuto, se encuentran comprometidos con un estándar determinado de conducta orientado a los fines del sistema tributario. A partir de este vínculo estatutario se encuentran fuera del sistema jurídico las actuaciones fraudulentas, abusivas, predatorias, arbitrarias, irracionales, irrazonables, los ilícitos atípicos, etc. En este contexto, el ciudadano debe actuar de buena fe, ${ }^{96}$ y se excluyen el actuar en abuso del derecho y el fraude de ley; ${ }^{97}$ y de parte de la Administración, bajo esos criterios de actuación racional y justificada de la Administración Tributaria, está presente la obligación de actuar de buena fe (principio de la confianza legitima, ${ }^{98}$ además del principio de legalidad), con exclusión del abuso del derecho, fraude de ley o desviación del poder. ${ }^{99}$

93 Sandra Álvarez, "Las potestades administrativas en la doctrina chilena 1859-2009", en Derecho Administrativo, 150 años de Doctrina, Rolando PANToJa (coord.), Santiago, Editorial Jurídica de Chile, 2009, p. 183.

94 Rafael Calvo Ortega, ¿Hay un principio de justicia tributaria?, Madrid, Civitas, 2012. A nuestro juicio, y no obstante la potestad política de los órganos públicos (en el contexto del Estado constitucional y democrático de derecho) "de definir el modo y la cuantía en que los ciudadanos deben contribuir a los gastos públicos” (Francisco José VILLAR RoJAs, Tarifas, tasa peajes y precios administrativos, op. cit., p. 9.), entendemos que ello no admite una total discrecionalidad, ya que hoy en día el único núcleo de certeza o de acuerdo que podemos tener a nivel institucional es el respeto de los derechos fundamentales y la limitación jurídica del poder del Estado (en ese marco, existe espacio para decisión política sujeta a derecho y racionalidad jurídica). Resulta necesario poner especiales filtros analíticos, dado que el establecimiento de cargas públicas de toda clase, la creación de figuras fiscales y parafiscales, y la imposición de limitaciones de cualquier tipo a la actividad y a los derechos fundamentales de los ciudadanos en el marco del sistema tributario, podrían atentar contra ese núcleo mínimo de arreglos institucionales válidos en un marco político y jurídico actualmente justificable.

95 Rodrigo CARAMORI, "Límites a la potestad tributaria y la carga tributaria en Brasil", Revista de Derecho 5 (2014), pp. 255-304. Se enfatizan los derechos fundamentales como límites de la potestad tributaria, pero también merecen ser considerados como su fundamento y pilar (principio normativo) (Patricio Masbernat, "Garantías constitucionales del contribuyente: crítica al enfoque de la doctrina nacional”, en Ius et Praxis 8 (2) (2002), pp. 299-357).

96 González Méndez, Buena fe y derecho tributario, Madrid, Marcial Pons, 2001.

97 Manuel Atienza y Juan Ruiz, Ilicitos Atípicos, Madrid, Trotta, 2006.

98 P. Díaz, El principio de confianza legitima en materia tributaria, Madrid, Tirant lo Blanch, 2014.

99 La desviación de poder puede resultar de una reacción de la Administración frente al formalismo jurídico (p. 92), pero también la Administración puede caer en abuso del Derecho (ATiEnZA y Ruiz MANERo, Ilicitos atípicos, Madrid, Trotta, 2006). 
Una vez establecida la legislación tributaria de mayor rango (leyes en sentido estricto y reglamentos generales en virtud de potestad reglamentaria autónoma y delegada) debe considerarse que la generación de las normas jurídicas secundarias y su aplicación exigen un debate público de carácter institucional regido por normas de procedimiento (administrativo y judicial) y de contenido que legitimen el acto de autoridad. Estos procedimientos exigen cumplir requisitos de corrección, es decir, sujetarse a las condiciones impuestas por los discursos práctico-racional y técnico-jurídico, y las propias de la argumentación jurídica. ${ }^{100}$

De ese modo se determina la OT específica y concreta de acuerdo con los mecanismos institucionales pertinentes, i.e., si se trata de aplicar reglas simples, mediante la mera operación silogística, pero de modo progresivo la variación gradual desde los casos menos fáciles a los casos difíciles (v. g., la aplicación de conjunto de reglas, reglas con contenido valorativo, principios, o un conjunto de las anteriores), exigirán operaciones de carácter interpretativo y justificativo cada vez más sofisticadas, y esas decisiones de carácter institucional.

La vinculación del ciudadano al sistema jurídico tributario es estatutaria, pero del estatuto no nace directamente una específica obligación de pago (un "tributo"). La OT de pago no es creada ni puede ser creada solo o directamente por la ley (obviamente, la ley es su antecedente esencial), dado que para nacer ella se requiere de una multiplicidad de condiciones fácticas y decisiones institucionales que, por cierto, tienen base (o se supone que la tienen) en la ley, pero no nacen sin más de la ley. En efecto, la configuración de la OT es una función de operación del sistema, en que intervienen diversas clases de normas y de órganos públicos dentro de sus competencias, considerando hechos concretos, y realizando operaciones de carácter interpretativo y justificativo. Es decir, en el marco del Estado constitucional y democrático de derecho, la potestad tributaria tiene otras características y finalidades y la OT presenta una estructura diferente a la que se dio históricamente en otros contextos jurídicos históricos predemocráticos o preconstitucionales.

En definitiva, de lo que se trata es de materializar, con criterios de certeza y controlabilidad (mediante la justificación racional y técnica de la decisión institucional de que se trate, sea determinación administrativa o judicial de la OT), la contribución de solidaridad que concretamente corresponde a cada contribuyente, conforme a los principios materiales y formales de la tributación, los que debieran iluminar no solo la generación de ley sino también todo el proceso de interpretación y aplicación de la misma, en toda la actuación administrativa o judicial. Estimamos, asimismo, que esta comprensión de la OT permite excluir o hacer innecesarias las limitaciones legales de los derechos fundamentales del contribuyente y la concesión de potestades amplísimas para la Administración Tributaria.

100 Para fundamentar mi punto de vista me apoyaré en la perspectiva de MAccormick, explicada por Carla FARAlli (La filosofia del derecho contemporánea, Madrid, Editorial de la Universidad Complutense de Madrid, 2007, pp. 209 y 210), Robert Alexy (“La tesis del caso especial”, en Isegoría 21 (1999), pp. 23-35) y Neil Maccormick (“Argumentación e interpretación en el Derecho”, en Doxa. Cuadernos de filosofia del derecho 33 (2010), pp. 65-78). 


\section{BIBLIOGRAFÍA}

Aguirre Román, Javier, Pedro García Obando y Ana Pabón Mantilla, “¿Argumentación o demostración en la decisión judicial? Una mirada en el Estado constitucional", en Revista de derecho 32 (1-29) (2009).

Alexy, Robert, "La tesis del caso especial”, en Isegoría 21 (1999), pp. 23-35.

Álvarez, Sandra, "Las potestades administrativas en la doctrina chilena 18592009”, Derecho administrativo, 150 años de doctrina. Rolando Pantoja (coord.), Santiago, Editorial jurídica de Chile, 2009.

Amatucci, Andrea (coord.), Tratado de derecho tributario, Bogotá, Temis, 2001.

ARnold, Brian J. y Hugh Ault, Comparative Income Taxation, 3 ed., Aspen Law, 2010.

Asís RolG, Rafael de, "El proceso de decisión. La interpretación”, Jueces y normas, Madrid, Marcial Pons, 1995.

Asís Roig, Rafael de, "La corrección del razonamiento", Sobre el razonamiento judicial, Perú, Ara Editores, 2005.

Aste, Christian, Curso sobre derecho y código tributario, Santiago, Thomson Reuters, 2013.

Atienza, Manuel y Juan Ruiz Manero, Ilicitos atípicos: sobre el abuso del derecho, el fraude de ley y la desviación de poder, Madrid, Trotta, 2006.

Ault, Hugh y Victor Thurony, Comparative Tax Law, Kluwer Law International, The Hague, Kluwer Law International, 2003.

Avi-YonaH, Reuven et al., "Comparative tax law: Theory and practice", en Bulletin for International Taxation 64 (3) (2010).

Avila, Humberto, Teoría de los principios, Madrid, Marcial Pons, 2011.

Avilés, Víctor Manuel, Legalidad tributaria y mecanismos antielusión, Santiago, Jurídica, 2014.

Aylwin, Patricio y Eduardo Azocar, Derecho Administrativo, Santiago de Chile, Editorial Universidad Nacional Andrés Bello, 1996.

Barguero, Juan Manuel, La función del tributo en el Estado social y democrático de derecho, Madrid, CEPC, 2002.

Barros Carvalho, Paulo, Curso de derecho tributario, Madrid, Marcial Pons, 2007.

Batistoni, Franco, Obbligazioni nel diritto tributario, Torino, Digesto, Leggi di Italia, 1994.

Beltrame, Pierre, Introducción a la fiscalidad en Francia, Barcelona, Atelier, 2004.

BRAITHWAITE, John, "Making tax law more certain: A theory", en Australian Business Law Journal 31 (2) (2003), pp. 72-80.

Buenaga Ceballos, Óscar, Metodología del razonamiento jurídico-práctico. Elementos para una teoría objetiva de la argumentación jurídica, Madrid, Dykinson, 2016. 
Calvo García, Manuel, Teoría del derecho, 2 ed., Madrid, Tecnos, 2000.

Calvo Ortega, Rafael, Curso de derecho tributario, Madrid, Civitas, 2011.

Calvo Ortega, Rafael, ¿Hay un principio de justicia tributaria?, Madrid, Civitas, 2012.

CARAMORI, Rodrigo, "Limites a la potestad tributaria y la carga tributaria en Brasil", en Revista de Derecho 5 (2014), pp. 255-304.

De Mita, Enrico, Principi di Diritto Tributario, Milano, Giuffre Editore, 2011.

DíAz, Patricia, El principio de confianza legítima en materia tributaria, Valencia, Tirant lo Blanch, 2014.

Edrey, Yoseph, "Constitutional Review and Tax Law: an Analytical Framework", en American University Law Review 56 (5) (2007), pp. 1187-1228.

Escribano, Francisco, La configuración jurídica del deber de contribuir, Perú, Editorial Jurídica Grijley, 2009.

FalsitTa, Gaspare, Corso Istituzionale di Diritto Tributario, 4 ed., Italia, Cedam, 2012.

FARALl, Carla, La filosofia del derecho contemporánea, Madrid, Universidad Complutense de Madrid, 2007.

FERreiro, José Juan, Instituciones de derecho tributario, Madrid, Marcial Pons, 2012.

FreEdman, Judith, "Improving (no perfecting) tax legislation: rules and principles revisited”, en British Tax Review 6 (2010), pp. 717-736.

Gaisbauer, Helmut et al., Philosophical Explorations of Justice and Taxation: National and Global Issues, Suiza, Springer, 2015.

Gallego, José Manuel, Los principios materiales de justicia tributaria, Granada, Comares, 2003.

García NovoA, Cesar, El principio de seguridad juridica en materia tributaria, Madrid, Marcial Pons, 2000.

García Novoa, Cesar, El concepto de tributo, Buenos Aires, Marcial Pons, 2012.

Giannini, Achille Donato, Instituciones de derecho tributario, Madrid, Editorial de Derecho Financiero, trad. de Fernando Sainz de Bujanda, 1957.

Giovannini, Alessandro, Il Diritto tributario per princìpi, Milano, Giuffre, 2014.

Giuliani Fonrouge, C., Derecho financiero, t. I, 10 ed., Buenos Aires, La Ley, 2011.

Goenaga, María, "Elementos principales de la cultura fiscal en América Latina”, Documentos de Trabajo, Instituto de Estudios Latinoamericanos 42 (2012).

González, Eusebio, "Los tributos extrafiscales en el derecho español”, Justicia y derecho tributario: libro homenaje al profesor Julio Banacloche Pérez, Madrid, La Ley, 2008, pp. 599-644.

GonzÁlez, Eusebio, "La revisión de la relación jurídica tributaria obligacional: las corrientes procedimentalistas”, en FORO, Revista de Derecho 9 (2008). 
González Méndez, Amelia, Buena fe y derecho tributario, Madrid, Marcial Pons, 2001.

Gribnau, Hans, Rivista di Diritto Tributario Internazionale (International Tax Law review) 3 (2012), pp. 9-42.

Guastini, Ricardo, Interpretar y argumentar, Madrid, Centro de Estudios Constitucionales, 2014.

Hensel, Albert, Derecho tributario, Madrid, Marcial Pons, 2005.

Jestaz, Phillipe, El derecho, Santiago de Chile, Editorial Jurídica de Chile, 1996.

Jones, J. Avori, “Tax law: Rules or principles?”, Fiscal Studies 3 (1996), pp. 63 y ss.

Kelman, Mark, Streategy or Principle? The Choice Between Regulation and Taxation, 4 ed., Michigan, The University of Michigan Press, 1999.

KiRchHof, Paul, "La influencia de la Constitución Alemana en su legislación tributaria”, en Base de datos Tirant OnLine, TOL314.020.

LuChenA, Gracia María "La relación jurídico-tributaria. El hecho imponible”, en Derecho financiero y tributario: parte general, Miguel Angel Collado Yurrita (dir.) 2013, pp. 255-268.

Lugui, Juan Carlos, La obligación tributaria, Buenos Aires, Depalma, 1999.

Maccormick, Neil, “Argumentación e interpretación en el Derecho”, DOXA. Cuadernos de filosofia del derecho 33 (2010).

MARÍN, Gloria, La relevancia jurídica de la motivación fiscal. Influencia del business purpose en el ordenamiento tributario español, Madrid, Dykinson, 2009.

Martín Mateo, Ramón, "La sustantividad del derecho administrativo", en Revista de administración pública 53 (1967), pp. 35-72.

Martín Queralt, Juan y Carmelo Lozano Serrano, Curso de derecho financiero y tributario, Madrid, Tecnos, 2013.

Martínez Lago, Miguel Ángel, "El hecho imponible”, en Derecho Financiero y Tributario, www.iustel.com. base datos IUSTEL, Documento RI §911733, (ESP): Portal Derecho, S.A., IUSTEL. Fecha de consulta: 14 de enero de 2017.

Masbernat, Patricio, C. Billardi, J. A. Fernández y M. A. Sánchez, "Los principios materiales de la tributación en las constituciones de Argentina, España e Italia. Algunas luces para la construcción de una dogmática en Chile”, en Revista de Derecho, Santiago, Universidad Católica de Valparaíso, 2013.

Masbernat, Patricio, "Principios constitucionales tributarios en la sentencia Roles № 1399-09-INA y № 1469-09-INA, acumulados, del Tribunal Constitucional, de 4 de noviembre de 2010: Referencia al caso 'Gerhard Schweinitz con SII', Corte de Apelaciones de Concepción, Rol 800-2010, de 1 de diciembre de 2010”, en Estudios constitucionales 9 (2) (2011), pp. 753-770.

Masbernat, Patricio, "Retorno al debate conceptual de tasa y tarifa como un parámetro de los limites del concepto de tributo. Comentario a la sentencia del 
Tribunal Supremo de España 5037/2015, de 23 de noviembre de 2015, recaído en recurso de casación 4091/2013”, en Revista Chilena de Derecho (2017) (en prensa).

Masbernat, Patricio, "El concepto de tributo y sus finalidades u objetivos", en Revista Tributária e de Finanças Públicas: RTrib 24 (129) (2016), pp. 155-192.

Massone, Pedro, Principios de derecho tributario, Santiago, Thomson Reuter, 2013.

Melo, Ignacio, La facultad interpretativa del Servicio de Impuestos Internos y los cambios de criterio, Santiago, Thomson Reuters, 2013.

MenÉndez, Agustín José, Justifying Taxes: Some Elements for a General Theory of Democratic Tax Law, Holanda, Springer, 2001.

Meza, Bárbara y David IBAcETa, "El principio constitucional de legalidad en materia tributaria”, en Cuadernos del Tribunal Constitucional 37 (2007).

Moreno SeIJAS, José Maria, La tasa y el precio público como instrumentos de financiación, Madrid, IEF.

Palao, Carlos, La aplicación de las normas tributarias y la elusión fiscal, Madrid, Lex Nova, 2009.

Pantoja Bauza, Rolando (coord.), Derecho administrativo: 150 años de doctrina, Santiago, Editorial Jurídica de Chile, 2009.

PARADA, Ramón, Concepto y fuentes del derecho administrativo, 2 ed., Madrid, Marcial Pons, 2012.

Parada VAca, Orlando "El juez en el Estado Constitucional", en Revista Iuris Tantum 13 (2012), pp. 7-9.

Pauner, Cristina, El deber constitucional de contribuir al sostenimiento de los gastos públicos, Madrid, Centro de Estudios Políticos y Constitucionales, 2001.

Pérez De Ayala, José Luis, Dinámica de la relación jurídica tributaria en el derecho español, Madrid, Dykinson, 1997.

Pérez De Ayala, Jose Luis (Miguel Pérez de Ayala Berrecil), Fundamentos de derecho tributario, Madrid, Dykinson, 2013.

Pérez Royo, Fernando, Derecho financiero y tributario. Parte general, Pamplona, Thomson Reuter, 2011.

Ponce De León, Sandra, "El contrato de concesión de obra pública en la legislación chilena”, en Revista de Derecho Público 79 (2013)-142.

PrebBle, John, "Should tax legislation be written from principles and purpose point of view or a precise and detailed point of view?", British Tax Review 2 (1998), pp. 112-123.

RAMíREz LudENA, Lorena, "Verdad y corrección en la interpretación jurídica", Revista de derecho (Valdivia) 28 (1) (2015), pp. 9-31.

Rivas, Estela, Los tributos atípicos, Madrid, Marcial Pons, 2006. 
Rodríguez García, José Antonio, "El derecho canónico como derecho estatutario en el ordenamiento jurídico español”, en Ius canonicum 39 (1999).

Romero, Felipe, El valor sistema tributario: acerca de su integración entre los principios de la imposición, Cádiz, Servicio de Publicaciones de la Universidad de Cádiz, 2005.

Russo, Pasquale, "La obligación tributaria", en Tratado de derecho tributario, Andrea Amatucci (dir.), Bogotá, Temis, 2001, pp. 17-43.

Scalinci, Costantino, Il Tributo Senza Soggetto, Italia, Cedam, 2011.

Siota, Mónica, Analogía e interpretación en el derecho tributario, Madrid, Marcial Pons, 2010.

SoRIANo, José, "Evolución del concepto 'relación jurídica' en su aplicación al derecho público", Revista de administración publica 90 (1979), pp. 33-78.

TAveira Torres, Heleno, Derecho tributario y derecho privado. Autonomía privada, simulación y elusión tributaria, Buenos Aires, Marcial Pons, 2008.

Tesauro, Francesco, Compendio di Diritto Tributario, 4 ed., Italia, Edit UTET, 2012.

Tiley, John y Gleen Loutzenhiser, Revenue Law, Oxford, Hart Publishing, 2012.

Tinelli, Giuseppe, Istituzioni di Diritto Tributario, Milan, Cedam, 2013.

VILlaR RoJas, Francisco José, Tarifas, tasa peajes y precios administrativos, Granada, Comares, 2000.

Weisbach, David A., "Formalism in the Tax Law", The University of Chicago Law Review 66 (3) (1999), pp. 860-886 Stable URL: http://www.jstor.org/stable/ 1600430 .

Zurita, Milenko, El acto administrativo tributario, Viña del Mar, Libromar, 2013. 